\title{
Off-The-Shelf or Tailored to Your Needs: IS CUSTOMIZATION ALWAYS SUPERIOR?
}

Customers are increasingly buying package offerings that consist of a combination of goods and/or services. They often have the choice of purchasing either an available standardized, off-the-shelf package or a customized offering designed to match their specific preferences. The position espoused in many books on one-to-one marketing and customer relationship management is that everyone is attracted to the latter. However, recent research is starting to challenge the universal appeal of mass customization. This project investigates if the preference for either a customized or standardized offer depends on whether they are experts or rather inexperienced in the product category. It further sheds light on repurchasing after buying standardized or customized products and if retailer reputation makes a difference.

\section{Buyer Expertise Influences Preferences}

In a study on either customized or standardized stereo systems, $67 \%$ of all respondents selected the customized version and only $33 \%$ selected the standardized system.

In another study, respondents rated their perceived expertise for stereo systems and if they would select either a customized (with sales person assistance) or standardized system for purchase. The more experienced the consumers felt (self reported expertise) the more likely they were to choose the customized system over the standardized system.

Even consumers who acknowledge having little expertise in the product category are attracted by customized offerings, though to a much lesser extent than consumers who feel confident in their knowledge of the category.

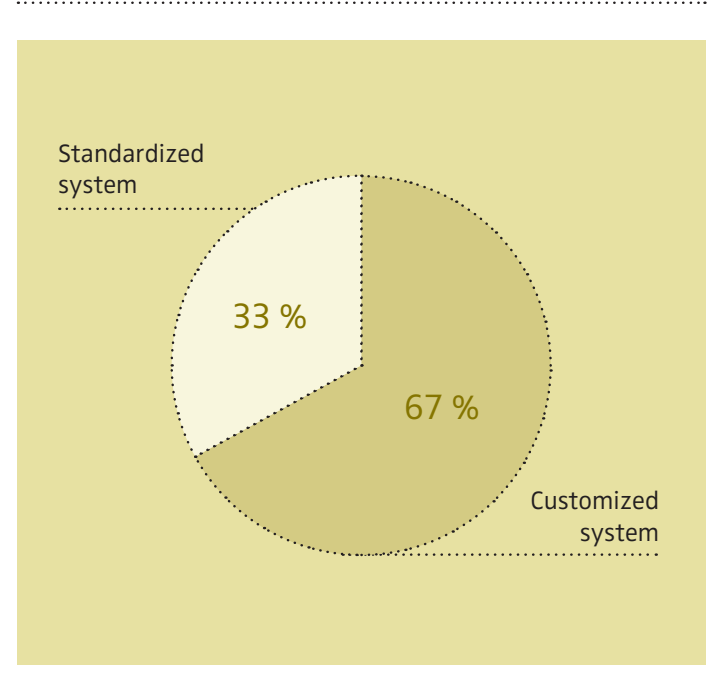

FIGURE 1:

Customized Systems are Preferred by a Majority 
FIGURE 2:

Experienced Consumers Prefer Customization Even More

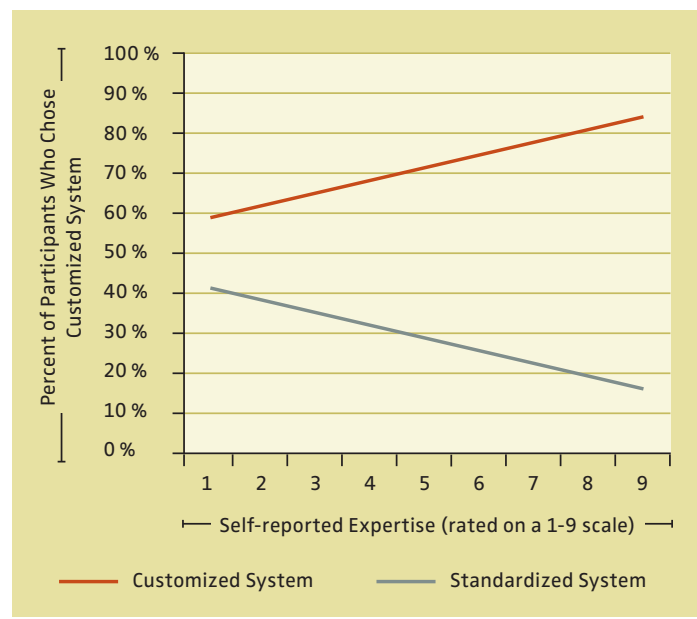

\section{Buyer Expertise and Retailer Reputation Influence Repurchase Intentions}

Two additional studies were conducted to examine patronage choice. These studies relied on computerbased shopping simulations, one in a traditional retail environment (for a home theater system) and the other in an online store (for a PC system). One objective was to investigate the effect of retailer reputation on preferences and repurchasing. Vendors were presented to have either a very high (five stars out of six according to independent ratings) or a rather poor reputation (two stars). Participants indicated their preference for different versions of individual elements (e.g. TV screen size, TV brand, DVD player brand, delivery for the home theater) and confidence levels in their preference. Then the actual purchase was simulated and subsequent questions on the perceived quality of purchasing and its result were answered.

Consumer confidence and retailer reputation both had an impact: consumers with low confidence in their preferences (versus high-confidence consumers) were relatively less willing to return to a retailer after purchasing a customized system. When reputation was taken into account, the observed effects were all more pronounced for the retailer with the lower reputation. Participants were less likely to return to a two-star retailer after
») The more experienced the consumers felt the more likely they were to choose the customized system over the standardized system. «

purchasing a standardized system than a customized one. For a five-star retailer, this difference was not significant.

Additionally, customization further seems to have positive effects on patronage choice. Participants were more willing to return to the same retailer for subsequent purchases after the purchase of a customized system.

\section{The Appeal of Customized Offerings is High but Not Universal}

The results suggest that customization does indeed have mass appeal, but consumers with less insight into their preferences are less willing to go back to the same retailer for future purchases after purchasing a customized (as opposed to standardized) system. Thus, although many consumers may find customization attractive, it is important for vendors to be strategic and discriminating when they determine which type of offering and accompanying degree of customization to provide to specific customers:

$>$ Prospective buyers who have strong preference insight are likely to want to have the freedom to work with a salesperson to create a customized solution that is best suited for them. 
$>$ Alternatively, potential customers with general requirements yet limited insight into their preferences may be good candidates for a standardized offering.

$>$ For less reputable retailers it is even more critical to identify an approach that fits the individual's buying preferences best.

Retailers should therefore ensure that their salespeople are adept at discerning whether a potential customer possesses insight into his or her preferences. Salespeople can undergo training to help them determine this so that they can proceed accordingly in their pre-sales activities. For example, salespeople may talk to customers and use the information gained from this interaction to propose the expanded offering deemed most appropriate. In instances when customers lack insight into their own preferences, salespeople may instead try to shape buyers' preferences and help them understand that the standardized system is a more viable option. The ability to suggest a standardized offer for this segment should yield trust not only in the salesperson, but also in the retailer, potentially stimulating future cross-sell and/or up-sell opportunities.

i) Participants were more

willing to return to the same

retailer for subsequent

purchases after the purchase

of a customized system.
The article is an adapted short version of: Bharadwaj, Neeraj, Rebecca Walker Naylor, and Frenkel Ter Hofstede (2009), "Consumer Response to and Choice of Customized versus Standardized Systems", International Journal of Research in Marketing, Vol. 26, $216-227$.

Contact person:

Neeraj Bharadwaj, Assistant Professor

Marketing \& Supply Chain Management, Fox School of Business, Temple University, Philadelphia, USA,

nbharadw@temple.edu

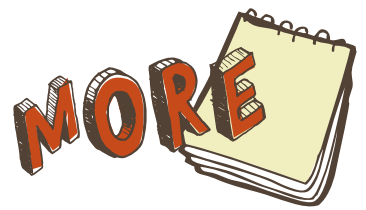

\section{KEYWORDS:}

Consumer Behavior, Customization, Standardization, Retailing, Systems Selling 